\title{
On the Historic Interaction between Learning and Media in Foreign Language Education
}

\author{
Qinglan $\mathrm{Yu}$ \\ Department of English, North China Electric Power University, Beijing 102206, China \\ Shuntao Zhang \\ School of Physics and Mathematics, North China Electric Power University, Beijing 102206, China
}

\begin{abstract}
The great "learning and media debate" has long been regarded as a milestone in the intellectual history of instructional technology, and it has also triggered new perspectives and breakthroughs on the study of this area. In this article, the author intends to draw a quick sketch of the progress of technological instructional media and the impacts they has exerted on foreign language education. In view of different language learning principles, this article also looks back upon the demands of learner needs on technological media, namely, from audio-lingual approach to current learner-oriented communicative approach. Eventually, the author describes the historic interaction between "learning" and "media" in the area of foreign language education, particularly from the traditional single media foreign language classroom to current multimodal classroom with multi-media representation in multiple environments. Finally, through a comprehensive analysis of "learning" and "media" in this specific micro context, the author intends to conclude that in the new digital era, the new foreign language education would feature itself with hyper-media representations, which would inevitably bring challenges to foreign language teachers-they should not be the traditional "sage on the stage", but to equip themselves with new perceptions and technologies, and to learn how to keep a dynamic, benign relationship between the student learning needs and the use of proper media.
\end{abstract}

KEYWORD: learning; media; foreign language education; instructional technology

\section{INTRODUCTION}

The relationship between education and media has long been an issue in the historic research of education. Since the very beginning of education, media has played an important role in education, from non-paper media, like tortoise shells, clay tablets, papyrus, and etc, to paper and printing media, like books, brochures, newspapers, magazines, and etc, to modern multimedia and hyper-media, like computers, smart-phones, PDAs, tablets and all other portable devices. The development in computer hardware and software now make it possible for creative visions to be realized easily and routinely. Domestic machine can play complex multimedia product, and easy-to-use tools allow the creation of complex imaginative work on the kitchen table. School-age children can shoot digital video, edit the high-quality moving pictures with the click of a mouse, author complex multimedia artifacts and upload them to millions of audiences on You Tube. What has been considered "mission impossible" is now everybody's game. The revolution driven by the present digital era would inevitably cover all areas of society, with education included at first.

As we know, educational institutions and private companies spend millions of dollars on technology annually, especially those colleges or universities who are eager to push forward the current education reform to adapt to the challenges of the digital era. In a period of MOOC and M-learning, new media, like internet and smart phone, even some fashionable applications, including "WE CHAT", "WE TALK", "TWITTER", or "FACEBOOK" played important roles in social collaboration, information transfer, education and many other fields of current society. Therefore, it is reasonable to re-explore the relationship between learning and media from specific perspectives. This paper would explore the historical interaction between learning and media in foreign language education in China. It will start from the very beginning of CALL, incorporate important stages of its historical development, and finally observe its most-updated pictures. The purpose of this historical review is not for a general summary or assessment. It aims to explore potential benefits and advantages of making the best use of current data-compressed era, and to help find 
solutions to existing problems occurring in foreign language education.

\section{THE HISTORIC DEBATE BETWEEN LEARNING AND MEDIA IN INSTRUCTIONAL TECHNOLOGY}

The media and learning debate in distance education has been on for several decades, and swept around the whole area with unprecedented force and scope. This debate start with Clark(Clark, 1983), who claims that instructional designers gains no learning benefits from employing a specific medium to deliver instruction. And any performance or time saving gains researchers observe are the result of uncontrolled instructional method or novelty. Clark dismisses studies that show the media can have an influence on student learning. He maintains that when examine the effect of media, only the media can differ. "All other aspects, including subject matter content and method of instruction must be identical" (Clark, 1983).

Robert Kozma responded to Clark in his article Learning with Media (Kozma, 1991) by pointing out that Clark's view of media as "delivery trucks" creates an "unnecessary schism between medium and method". He proposes an alternate theory of learning: the learner strategically manages the available cognitive resources by extracting information from the environment and integrating it with information already stored in memory".

According to Kozma (Kozma, 1994), media are an integral part of the instructional design process. $\mathrm{He}$ compares text, audio and video media and outlines their strengths and weaknesses as learning tools. Some students might learn a task very well regardless of the delivery device. For other, though, Kozma believes that a careful use of media will enable learners to take advantage of its strengths and to construct knowledge.

Jack Kourmi (1994) also enters the debate and argues that researchers (like Clark) promulgate the "false impression of equipotentiality between media". He points out that "here has rarely been any control of production quality between the media being compared" and "most experiments take no account of the professional competence of the production team". He finally asserts that with limited experience, time and budgets, it is no wonder that poorly produced audio-visual materials produce the same learning results as a printed text. In addition, Koumi also argues that many studies take no account of the learning styles of students, nor the purpose for which they are using the medium. As well, Koumi argues that people fail to incorporate learner's attitudes to media. Therefore, it might be the case that students may take televised programs lightly and thus fail to put the effort required to learn as effectively as they could. So Koumi suggests that researchers should move away from "media comparison" and try to develop and refine criteria for pushing media to best effect.

In response to Koumi's thesis of "false equipotentiality", Kozma maintains that instructional designers must carefully design their content to take full advantage of various media because each media has its unique qualities. He further argues that methods can not be transferred from one medium to another-if designers change the medium, they must completely change their method.

Clark, however, strongly refutes Koumi's criticism. He argues that people have "confounded" the discussion. In a later article (Clark 1994) he repeats his claim that media attributes are not casual in learning-what they are is casual in the cost effectiveness of learning. He emphasizes that media is not an integral part of method and media do indeed have equipotentiality. Clark insists that all methods can be delivered by a variety of media and media attributes, and what designers must choose is the least expensive and the speediest.

Virtually, the great learning and media debate will likely carry on; whatever the study, proponents in either camp will likely find fault with it. With the proliferation of educational technologies in the past 20 years, however, researchers would do well to worry less about comparisons of media and instead focus their attention on making the best use of each.

\section{THE HISTORIC INTERACTION BETWEEN LEARNING AND MEDIA IN FOREIGN LANGUAGE EDUCATION}

\subsection{Terminologies of CALL}

The history of foreign language education also reveal the ups and downs of "machine" or "computer", or say, "media", particularly reflected in terminologies and key concepts. Beatty (2003) rounds up the terms used by a range of developers to label the projects they are engaged in, like CALT (Computer-Assisted Language Teaching), CALI(Computer-Assisted Language Instruction),

CALT(Computer-Assisted Language Teaching), CALL(Computer-Assisted Language Learning), , $\mathrm{CMI}$ (Computer-Mediated Instruction), CMC(Computer-Mediated Communication), TELL(Technology Enhanced Language Learning), WELL( Web-Enhanced Language Learning), and etc. Some of these terms are compatible in property and nature, even lead to the doubt that if different terms genuinely referred to one and the same thing. However, if a terminology has been generated and accumulated over a period of time, we should not necessarily dismiss its items as mere redundancies. Virtually, terminologies are implanted with historical values and significance. Therefore, a 
minor change in a pair of similar terminologies might indicate a mile-stone progress in academic research. The historic relationship between learning and media is also reflected in terminologies. Skinner(1968)maintains that "machine instruction would permit each student to proceed at his own rate". He simply says "machine instruction", so why in the popular terminology CAI, the word "assisted" is added? A deep insight into the history of computer assisted instruction in 1960s reveals that those early computer enthusiasts had once dreamed replacing human teacher with computer or other machine. When this ambition turns out to be an untenable proposition, they reset their research goals and added the word "assisted". Skinner's original "machine instruction" was out, and in came the idea of using the computer to assist human teachers. The relationship between a computer and a human teacher was thus redefined. Although the progress from "machine instruction" to "computer assisted instruction" is not directly related to the famous "learning" and "media" debate in the field of instructional technology, it could be reasonably one part of that big picture, and also a good reflection of people's perception of the role "media" has played in language instruction. In the article, the author take the most commonly known terminology "CALL(Computer Assisted Language Learning)" as key word, to help view its historic development, consequently to help explore the relationship between English "learning" and technology "media".

\subsection{The historical development of CALL in view of learning and media}

Generally, the historical development of CALL could be mainly divided into three periods, the textbased CALL, the multimedia-based CAll, the network based CALL, and this article extends the third phase into a new stage, the new hyper-media based CALL in digital era.

\subsubsection{The text-based CALL in 1960s and 1970s}

In the 1950s and early 1960s, empiricist theory was predominant in language teaching. As described by Stern, empiricist theory is "pedagogically audiolingualism, psychologically behaviorism and linguistically structuralism". The principles from these three schools were mutually supportive when applied to language teaching and learning. In an empiricist influenced foreign language classroom, the teacher presented new vocabulary and structures through dialogues which students learned through imitation and repetition, key structural patterns were extracted from the dialogues and used as the basis for pattern drills, and successful responses were positively reinforced. Skinner(1957) points out that the central elements of behaviorism, stimulus, response, and reinforcement, which had a deep influence on foreign language teaching practice, particularly triggered the widespread introduction of language laboratory, a important form of technology in enhancing language learning. Skinner was largely instrumental and he advocated the use of teaching machine, and later programmed instruction became very influential.

The text-based CALL in 1960s and 1970s are mainly CAI (Computer-Assisted Instruction), involving team efforts that were well funded. The two prominent projects, costing approximately five million dollars each, were the PLATO and TICCIT projects, both of which were used to teach foreign languages as well as other objects. Plato was designed to provide interactive, self-paced instruction for large number of students. It supported communication between users in from of notes files and "talk" with email system. Within this framework, the teacher does not have to learn a computer language, and he could feel comfortable with the instructional design built into the system, and his duty is to control over the material content. Murphy and Appel had conducted independent assessment on Plato system, the result shows that this system is very appealing to both teachers and students, but work on system does not have consistent positive or negative effect on student achievements or attrition rates. Therefore, Plato, the large scale, money-consuming technology media shows no significant positive influence on learning outcome, which in one way back up Clark's view on media's role as "delivery truck".

\subsubsection{The multimedia-based CALL in 1980s}

1980s witnessed the far-reaching approach of language teaching, Communicative Language Teaching(CLT), which makes communicative competence the goal of language teaching and develop procedures for the teaching of the four language skills. Rapid change was taking place in computing. The early 1980s saw a boom in CALL largely due to the introduction of the microcomputers. Language-teacher programmer became prominent, and some of them could write simple CALL programs with a version of BASIC language, ranging from text reconstruction, gapfilling, speed-reading, simulation, vocabulary game and etc. Under this framework, the language teachers not only played a role in developing CALL materials, but also in integrating the computer activity into the lesson as a whole. Commentators and researchers had shifted their emphasis on the debate between learning and media, focusing more on what learners could do with it, that is, the importance of methodology in CALL. The most famous authoring program genre of the 1980s is the Storyboard program written by John Higgins. It is text-reconstruction program, alongside gap-filling, text manipulation, and simulation. According to 
Pederson(1988), meaningful CALL practice is both possible and preferable, and learner differences can affect learner strategies, learning gains, and attitudes, and all those differences could be documented easily and accurately thorough computer. And he also noted that many language teachers are dissatisfied with existing software and desire training on how to integrate CALL into the existing curriculum. When empirical theory predominant, there appeared to be a perfect match between the qualities of the computer and the requirements of language teaching and learning. However, during the CALL methodology context, researcher and teacher's dissatisfaction indicates that the ever-growing learning needs challenges the existing media and technology, calling for the upcoming of more sophisticated, advanced media.

\subsubsection{The net-worked based CALL in 1990s}

It is well-known that one of the most significant developments in technology is the Internet, the worldwide "network of networks". It is a giant heap in human history. Projects which initially require expensive, specialized hardware soon became available to all those who have access to widely available generic models of computers. Similarly, long-distance network interactions, like the "talk" function in the PLATO Project were open to a much wider population than was previously possible, and in a much refined form. In 1994, the Oral Language Archive(OLA) was initiated at Carnegie Mellon University in 1994. Its goal is to establish a collection of digital sound recordings for foreign language learning that is accessible from around the world via the Internet. As well as the sound archive itself, the OLA contains a suite of management tools to enable users to locate and use sound segments easily and flexibly. And the recordings are segmented and coded for various attributes such as level of formality and complexity. Users will be able to search the archive by language, gender of speakers, grammar trait, function, topic, formality, subject keywords, and lexical difficulty. To use of these resources, users will only require log-on privileges and, as a resource on the Internet, many users will be able to access the materials simultaneously. What is noticeable is that the notion of learning environment came into being, and a lot of CALL programs focus not only in learning resources, but also in learning environment. the computing environment provides the learner with tools and information to facilitate the learning of languages. Therefore, with the powerful tool of Internet, the efficiency and effects is greatly facilitated. As Internet is now available to both learners and teachers, particularly with the functionality it provides, notably in terms of access to and interactivity with new materials, people and learning environment, it is crucial to understand
CALL in this period represents more than one homogeneous type of activity.

\subsubsection{The hyper-media based CALL in digital era}

Many language learners prefer the current network based CALL because it provides rich methodologies and resources. As we know, it integrates e-texts, images, graphics, animations, 3Ds, sounds, videos, as many as we could name. However, networkbased CALL is often cursed for the slow access or a broken linkage, or for being messed up because too many learners get access to one website at the same time.

Stepping into the 21 century, the flourishing development of Internet and Cloud technology brings both chances and challenges to foreign language Educations. With Internet speed as high as $100 \mathrm{Mbites} / \mathrm{second}$, as well as powerful smart phones, wearable PDAs, Tablets, Portable DVD players, and free WIFI service in most universities campus, the fast-growing hyper media development would inevitably foster the efficiency of learning to an unprecedented stage. Many prestigious universities, like Cambridge, Oxford, present a lot of free online course. Micro Class, MOOC (Massive Open Online Course), M-learning (mobile learning), flipped classroom, a lot of new terminologies bombard the field of education, particularly the field of foreign language education. As we know, what is happening in Chinese foreign language education field is the calling for a new reform by applying digital technology in teaching and learning. All academic conferences are held to help people get familiar with terminologies like MOOC, or flipped classroom. A lot of universities and high schools organize Micro-Class context, to start the reform from the very base. The ministry of Education and other government organizations offer very pleasant funding for digital foreign language education research and practice. As a result, new research articles are published in academic journals, and some education institutions, universities and even publishers have developed smart software or platform to facilitate foreign language learning. In China, Beijing Foreign Language Teaching and Research Press (FLTRP) published a lot of new textbook and their relevant audio and visual products, including "new horizontal" series, "new standard" series, together with its online platform and resources for learner's before-class and afterclass autonomous learning. FLTRP also issued some professional digital tools to meet the various needs for teachers and learners, such as I-Test (a automatic test paper system which could help teacher make high-quality test paper on the assigned content), IRead(an automatic grading system which could help teacher grade student's online writing), I-Research (an network application which release the latest news on foreign language education and research by 
WECHAT ). Many education service companies also presented many high-quality digital tools, such as, Bingo, Lore (Learn More), which are very convenient for teacher and student interaction. With those platforms, teachers could post all reading materials, give comments on student's work, grade student's work, and students could submit their homework, view teacher's comment on their work, or interact freely with other classmates.

\section{CONCLUSION}

Virtually we are living in a hybrid world of mixed media. Traditional textbooks are still alive, and modern pre-digital multimedia refuses to die out quickly. Digital hypermedia is simply evolving at a dazzling speed. Traditional media forms, from books through to animation and live action film and television, are fixed linear texts, unfolding in only one narrative order determined by the creator. With the arrival of multimedia, new possibilities have come to the fore: first hypertext and now hypermedia. This new paradigm presents the greatest creative challenge since the arrival of writing. New multimedia forms will grow, as all new media do, from their immediate predecessors. As what had happened in the past, a lot of technological media, such as telegram, telex or the newsreel, and the once-poplar tape-recorder, had quickly eclipsed by subsequent development. Therefore, some researchers even worry if the CD-ROM and its silver disk successors become the new papyrus or just a footnote in the history of foreign language education.

The ups and downs of media and learning in foreign language education partly form a dialectical duo, which reveals the historic interaction between foreign language education and the assisted media. In audio-lingual approach dominant period, the wide application of language laboratory played a positive role in facilitating foreign language learning, however, in communicative approach dominant period, many researchers are not satisfied with the quality of course ware and managed to create education programs by themselves. Therefore, it is clear that the assistance media might help (if it exactly matches the speed of learning theory development), or hinder (if it falls behind the growing learning needs) the effect and efficiency of learning. The best idea is to achieve a dynamic balance between language learning and media development. What is critical in the emerging digital era is to make the best use of the super interactivity between user and media, and to create unlimited, non-linear learning resources, platforms and devices.

As for teachers, they should adjust their role to meet the coming challenges. It is commonly agreed that technology won't replace teachers, but teachers who use technology will probably replace teachers who do not use it. Therefore, teachers should not be the "sage on the stage", but to adjust themselves into a cooperator or a guide for student's individual learning.

We are looking forward to a future with various education applications on learner's smart phones or tablets, and with a highly-interactive, user-friendly language classroom, which could help learner's with authentic learning resources, convenient tools for learner to facilitate their learning efficiency, smart learning platforms fit for every individual's learning style and speed, and efficient supervising and monitoring modules to help regulate each learner's behavior.

\section{ACKNOWLEDGEMENT}

This work is supported by Beijing Higher Education Young Elite Teacher Project (YETP07312014BJ01 63)

\section{REFERENCES}

[1] Beatty,K. 2003. Teaching and Researching ComputerAssisted Language learning. London: Longman.

[2] Clark, R. E.1994. Media Will Never Influence Learning. Educational Technology Research and Development, 42(2):21-29.

[3] Clark, R.E. 1983. Reconsidering Research on Learning from Media. Review of Educational Research,53(4): 445459.

[4] Koumi, J. 1994. Media Comparison and Development: A Practitioner's View. British Journal of Educational Technology, 25(1):41-57.

[5] Kozma, R.1991. Learning with Media. Review of Educational Research, 61(2), 179-211.

[6] Kozma, R.1994. A Reply: Media and Methods. Educational Technology Research and Development, 42(3), 11-14.

[7] Pederson, K.M.1988. Research on CALL. In W.F. Smith, Ed., Modern Media in Foreign Language Education: Theory and Implementation. Lincolnwood: National Textbook Company.

[8] Skinner,B.F.1957. Verbal Behavior. New York: Appleton Century Crofts.

[9] Skinner,B.F.1968. The Technology of Teaching. New York: Appleton Century Crofts. 